\title{
Morphology and thermoluminescence properties of terbium doped magnesium orthosilicate
}

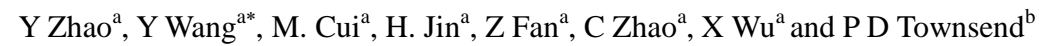 \\ ${ }^{a}$ School of Science, China University of Geosciences, Beijing, 100083, China \\ ${ }^{\mathrm{b}}$ Science and Technology, University of Sussex, Brighton, BN1 9QH, UK
}

\begin{abstract}
The morphology and structural form of Tb doped magnesium silicate are reported as a function of the dopant concentration of $\mathrm{Tb}$. The preparation method is described. This includes a sintering step which is time sensitive and an optimum processing time is discussed to improve dosimeter sensitivity. The thermoluminescence spectra are remarkable as they reveal peak shifts in the temperature of the characteristic lines of the Tb dopant. A model related to charge capture by different upper state orbitals of the rare earth transitions is offered. Optically stimulated luminescence data are also included.
\end{abstract}

Key words: $\mathrm{Mg}_{2} \mathrm{SiO}_{4}$ : $\mathrm{Tb}$; Thermoluminescence; Photoluminescence; Optically stimulated luminescence.

\section{Introduction}

Magnesium orthosilicate doped with terbium $\left(\mathrm{Mg}_{2} \mathrm{SiO}_{4}: \mathrm{Tb}\right)$ was first introduced for consideration in radiation dosimetry in 1971(Hashizume et al., 1971; Jun and Becker, 1975). Due to its high sensitivity and moderate photon energy dependence (Furetta, 2003), it is a very attractive dosimeters material as it shows a very high gamma sensitivity, which is $40-100$ times that of LiF: Mg, Ti. An even more attractive feature of $\mathrm{Mg}_{2} \mathrm{SiO}_{4}$ : $\mathrm{Tb}$ is that it has the highest intrinsic TL sensitivity to UV radiation (wavelength $253.7 \mathrm{~nm}$ ) (Lakshmanan et al., 1978). Thus it has a potential as a candidate material for the environmental and personal monitoring. Several studies have already been carried out on the dosimetry properties of $\mathrm{Mg}_{2} \mathrm{SiO}_{4}$ : $\mathrm{Tb}$ (Nakajima,

\footnotetext{
*Corresponding author, wyfemail@gmail.com
} 
1972; Mittani et al., 2008; Lakshmanan and Vohra, 1979; Bacci and Furetta, 1992). The response of $\mathrm{Mg}_{2} \mathrm{SiO}_{4}$ : $\mathrm{Tb}$ with different irradiation sources has been revealed and the appearance of a 220 ${ }^{\circ} \mathrm{C}$ glow was seen only after laser irradiation (Miyoshi et al., 2004). Because of its high response to gamma irradiation, terbium-doped magnesium silicate has been used for the first time as a FOD (fiberoptic radiotherapy dosimetry) dosimeter to assess the in vivo, real time dose (Molina et al., 2010).

As mentioned in our earlier studies (Wang et al., 2014; Zhao et al., 2015), the characteristics of terbium-doped magnesium silicate vary considerably with the production techniques. Glow curve shapes and TL intensities are strongly influenced by the preparation method, because there are a range of phases of the $\mathrm{MgO}-\mathrm{SiO}_{2}$ system and the performance depends on the activator concentration. In addition, the performance is sensitive to the temperature and duration of the sintering process. Fortunately, these variables are nominally controllable.

Although TL properties of $\mathrm{Mg}_{2} \mathrm{SiO}_{4}$ : $\mathrm{Tb}$ have been studied for decades, the structure and morphology of this material has not been reported before. In this paper, a comprehensive work is presented on the detail of $\mathrm{Mg}_{2} \mathrm{SiO}_{4}$ : Tb which includes crystallographic phases, morphology, luminescence properties and TL parameters that offer a better understanding of this material.

According to our previous studies on the synthesis conditions which could influence and control the TL response of $\mathrm{Mg}_{2} \mathrm{SiO}_{4}: \mathrm{Tb}$ (Wang et al., 2014), sintering temperature is a critical factor for the generation of $\mathrm{Mg}_{2} \mathrm{SiO}_{4}$. Thus, all the samples reported in this paper have been sintered at $1650{ }^{\circ} \mathrm{C}$ (which is the limitation set by furnaces in our laboratory).

\section{Material and Methods}

$\mathrm{Mg}_{2} \mathrm{SiO}_{4}: \mathrm{Tb}$ sample was prepared by a high temperature solid-state reaction. According to 
the stoichiometric ratio, the raw material of $\mathrm{Mg}(\mathrm{OH})_{2} \cdot 4 \mathrm{MgCO}_{3} \cdot 5 \mathrm{H}_{2} \mathrm{O}, \mathrm{SiO}_{2}$, with different concentrations of $\mathrm{Tb}_{2} \mathrm{O}_{3}$ (99.99\%) were mixed thoroughly in an agate mortar and then pressed. The mixture was placed in an alumina crucible and then fired at $1650{ }^{\circ} \mathrm{C}$ in the furnace for different periods of time. After cooling down naturally, the fired samples were then ground into powder and meshed for measurements.

$\mathrm{X}$ ray diffraction (XRD) measurements were performed to identify the crystallographic phases. The scan rate is $2^{\circ} \min ^{-1}$ and the range was from $20^{\circ}$ to $70^{\circ}$. The microstructures of samples were measured by Hitachi's S-4800 field emission scanning electron microscopy (FESEM).

Photoluminescence (PL) emission spectra were recorded with a JY FluoroMax-4 system. A xenon lamp was used as the excitation source. Thermoluminescence and optically stimulated luminescence (OSL) were recorded by a TOSL-3DS three-dimensional spectrophotometer. The temperature range is from $30{ }^{\circ} \mathrm{C}$ to $400{ }^{\circ} \mathrm{C}$ for glow curve test and from $30{ }^{\circ} \mathrm{C}$ to $500{ }^{\circ} \mathrm{C}$ for three dimension test. The heating rate is $5{ }^{\circ} \mathrm{C} / \mathrm{s}$ and the samples were pre-exposed to $100 \mathrm{mGy}$ with a ${ }^{60} \mathrm{Co}$ irradiation source. The OSL was excited by a LED lamp whose central wavelength is 830 nm.

\section{Results}

\subsection{Structural properties}

\subsection{1 $\mathrm{X}$ ray diffraction analysis}

The XRD patterns of $\mathrm{Mg}_{2} \mathrm{SiO}_{4}$ : Tb with different doping concentration is shown in Fig. 1. The results indicate that all the diffraction lines correspond to the orthorhombic phase of pure magnesium silicate (JCPDS \#04-0768). Although the peak intensities of some diffraction lines vary with doping concentration, the activator $\left(\mathrm{Tb}^{3+}\right)$ does not affect the main phase structure of 
$\mathrm{Mg}_{2} \mathrm{SiO}_{4}$.

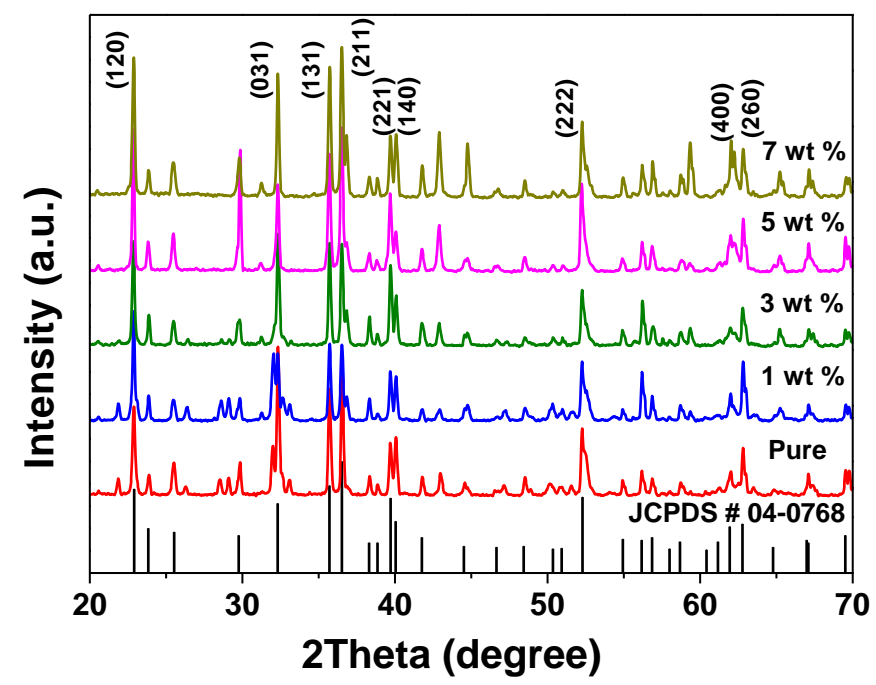

Fig. 1. XRD patterns for un-doped (pure) and $\mathrm{Tb}^{3+}$ doped $\mathrm{Mg}_{2} \mathrm{SiO}_{4}$

\subsubsection{SEM characterization}

The SEM images of $\mathrm{Mg}_{2} \mathrm{SiO}_{4}$ : Tb are shown in Fig. 2. Fig. 2(a) is for the sample which was sintered for an hour and whose doping concentration is $1 \mathrm{wt} \%$. Fig. 2(b) is for the sample with the same preparation condition but a different doping (7 wt $\%$ ). Both samples have flake crystalline structures and similar size.

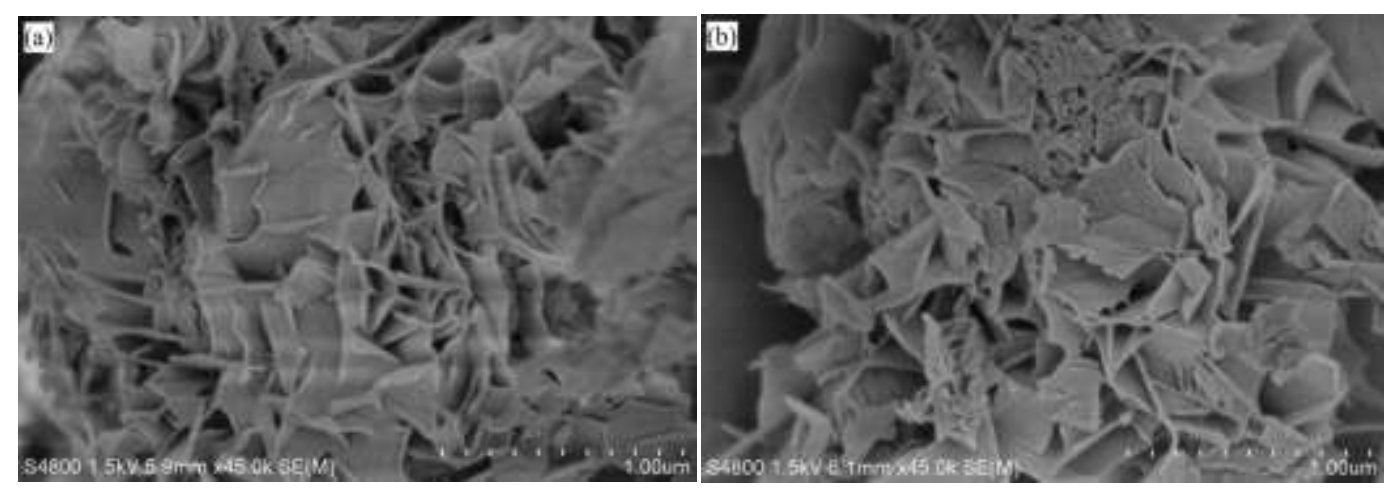

Fig. 2. SEM images of $\mathrm{Mg}_{2} \mathrm{SiO}_{4}$ : $\mathrm{Tb}$ with different doping concentration (a) is for $1 \mathrm{wt} \%$ (b) is for $7 \mathrm{wt} \%$

\subsection{Luminescence properties}

\subsubsection{Photoluminescence}

Photoluminescence (PL) spectra of the $\mathrm{Mg}_{2} \mathrm{SiO}_{4}$ : Tb is shown in Fig. 3. The sample used here 
is the sample which was sintered for an hour with the $1 \mathrm{wt} \%$ terbium. The excitation wavelength was $377 \mathrm{~nm}$ giving, as expected, the characteristic lines of $\mathrm{Tb}^{3+}$ at 438, 488, 542, 585 and $623 \mathrm{~nm}$.

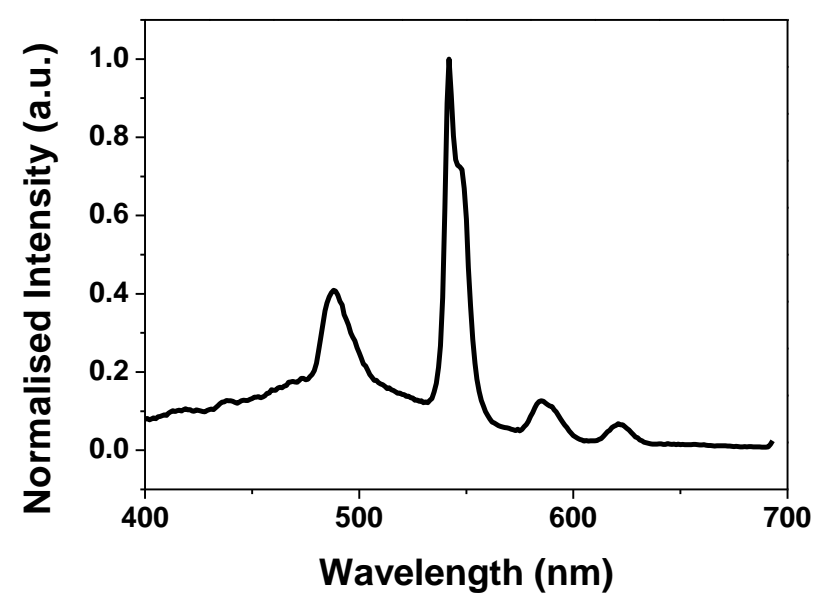

Fig. 3. PL emission spectra of $\mathrm{Mg}_{2} \mathrm{SiO}_{4}$ : $\mathrm{Tb}$ (excited by $377 \mathrm{~nm}$ ).

3.2.2 Optically stimulated luminescence (OSL) spectra

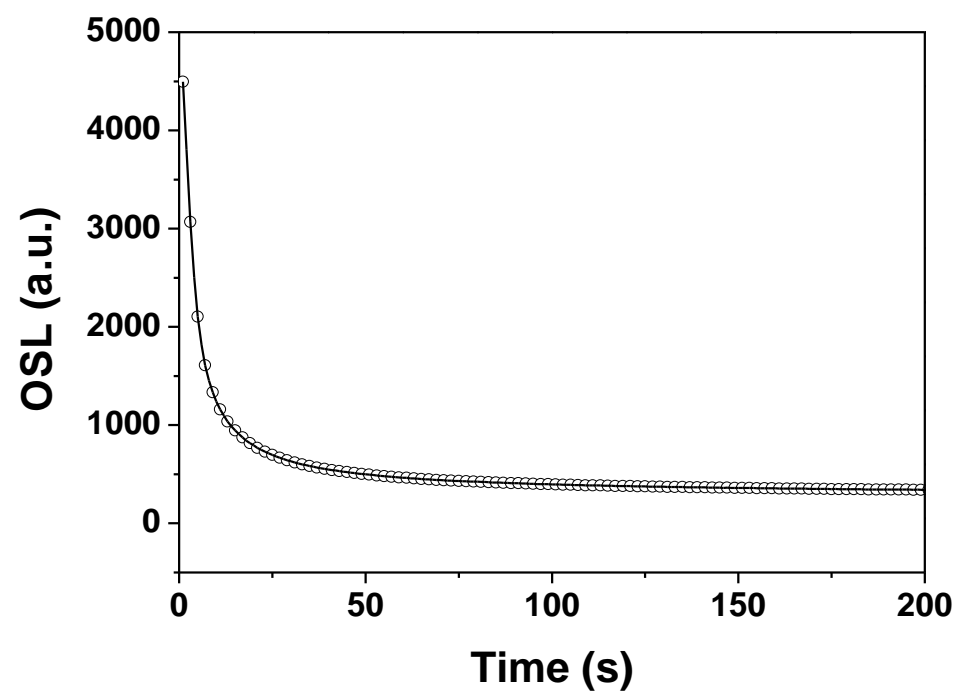

Fig. 4. OSL signal decay from $\mathrm{Mg}_{2} \mathrm{SiO}_{4}$ :Tb stimulated with an IR LED

In addition to good thermoluminescence properties, $\mathrm{Mg}_{2} \mathrm{SiO}_{4}$ : $\mathrm{Tb}$ has a useful optically stimulated luminescence after being stimulated with infrared light excitation. An OSL curve is shown in Fig. 4.

\subsubsection{Thermoluminescence spectra}

The isometric and contour plots of thermoluminescence signal from $\mathrm{Mg}_{2} \mathrm{SiO}_{4}$ : $\mathrm{Tb}$ are shown 
in Fig. 5. Fig. 5(a) is an isometric TL spectra and Fig. 5(b) is the contour plot. The sample used here is the sample which was sintered for an hour with the $1 \mathrm{wt} \%$ terbium. The main glow peak is at $315{ }^{\circ} \mathrm{C}$. The TL emission equipment offers more sensitivity than that used for the PL. The glow curves of the main emission bands are compared in Fig. 6. Of particular note is an unexpected feature that there are temperature differences as a function of wavelength. Details are presented in Table I.

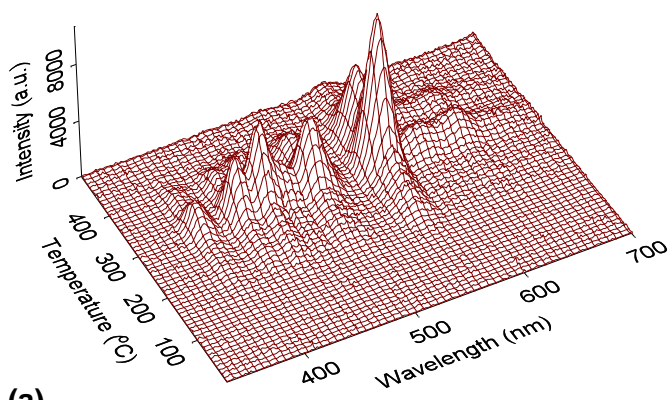

(a)

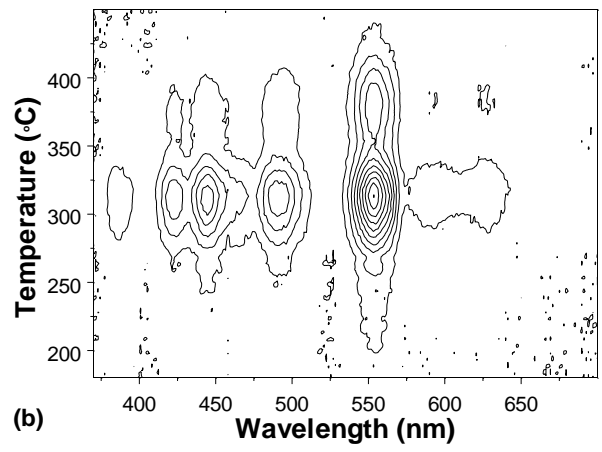

Fig. 5. The TL spectra of $\mathrm{Mg}_{2} \mathrm{SiO}_{4}$ : $\mathrm{Tb}$ (a) is isometric plot and (b) is contour plot.

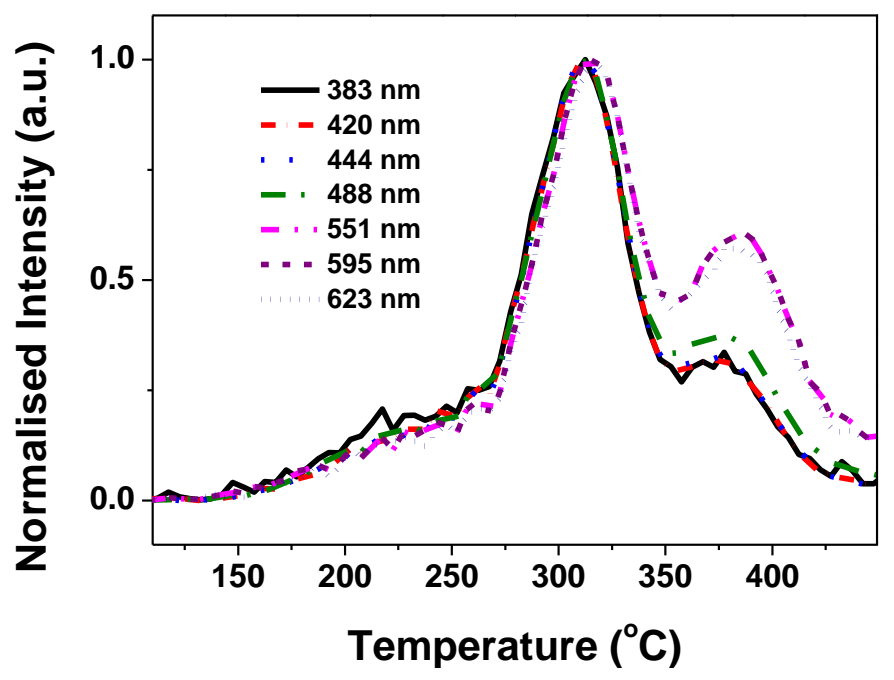

Fig. 6. Examples of the TL spectra of $\mathrm{Mg}_{2} \mathrm{SiO}_{4}$ : $\mathrm{Tb}$ as a function of wavelength.

Table I. High temperature glow peaks for $\mathrm{Mg}_{2} \mathrm{SiO}_{4}: \mathrm{Tb}$

\begin{tabular}{cccccccc}
\hline Wavelength $(\mathbf{n m})$ & $\mathbf{3 8 3}$ & $\mathbf{4 2 0}$ & $\mathbf{4 4 4}$ & $\mathbf{4 8 8}$ & $\mathbf{5 5 1}$ & $\mathbf{5 9 5}$ & $\mathbf{6 2 3}$ \\
\hline Peak1 $\left({ }^{\circ} \mathrm{C}\right)$ & 313 & 313 & 313 & 313 & 317 & 317 & 317 \\
Peak2 $\left({ }^{\circ} \mathrm{C}\right)$ & 377 & 377 & 377 & 377 & 387 & 387 & 383 \\
\hline
\end{tabular}


The glow curves are sensitive to the dopant concentration and examples are shown in Fig. 7. All the sample of different doping level were sintered for an hour. Overall there are three distinct glow peaks which are near $210{ }^{\circ} \mathrm{C}, 315{ }^{\circ} \mathrm{C}$ and $370{ }^{\circ} \mathrm{C}$ at this low heating rate in the spectral system.

Similar results are shown in Fig. 8 but for different sintering times. This indicates how the duration of the sintering time has an effect on the response from the same irradiation dose. The changes in glow curves response are shown in Fig 8(a). Fig 8(b) gives the dependence of peak value of (around $300{ }^{\circ} \mathrm{C}$ ) with sintering time and one hour is the most effective value for the material used here. (Perhaps a slightly shorter time might offer further improvement.) Additionally, other heat treatments, such as a low temperature annealing treatment after grinding the sinter into powder might offer further improvement. This is a further avenue that will be explored in the overall optimization of the performance.

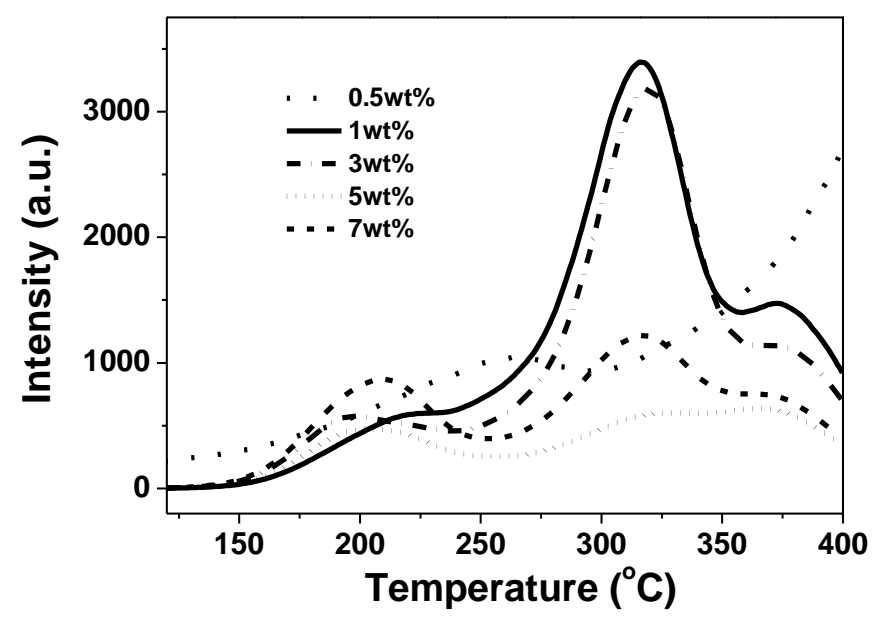

Fig. 7. Glow curves with doping concentration. 

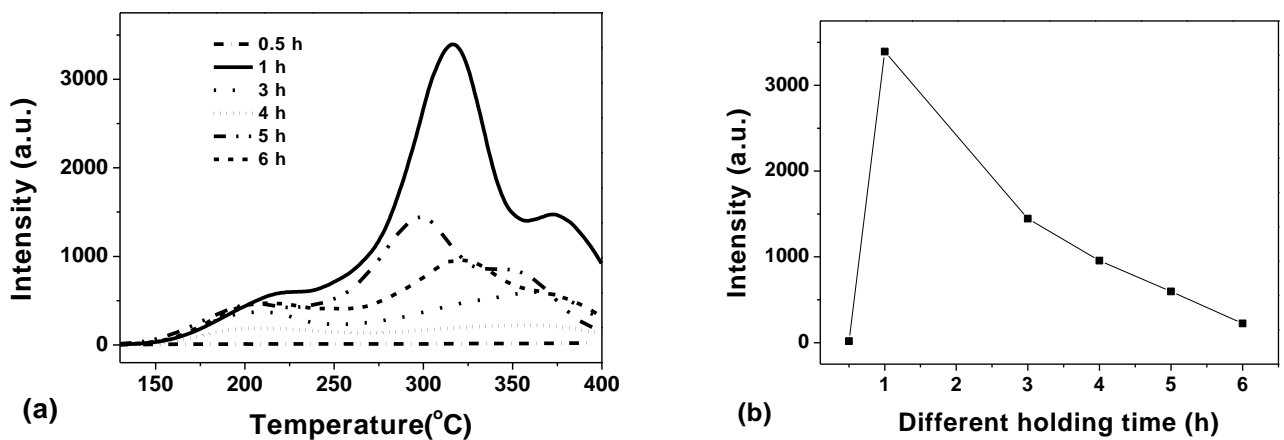

Fig. 8. (a) The glow curves with different sintering time (b) TL intensity changes with sintering time

It is conventional to attempt to de-convolute glow curves into their component features and, for comparison purposes with other work, this is also reported here. Nevertheless, as stated in many articles (Ege et al., 2007) for a heating rate of 5 degrees per second there are increasing differences between the monitored heater temperature and the sample. Hence the numbers presented are useful in comparisons, but not on an absolute basis. Further, errors will exist in the precise temperature values that are cited for high heating rates. TL data from the samples were processed by the data processing software provided by the maker of TOSL-3DS TL reader. The curves were deconvoluted using a general order kinetic curve-fitting method modified by Chen et al. (Mohan and Chen, 1970; Shenker and Chen, 1971) as following the equation of

$$
I(T)=n_{0} s \exp (-E / k T) /\left\{1+[(b-1) s / \beta] \cdot \int_{T_{0}}^{T} \exp (-E / k T) d T\right\}^{b /(b-1)}
$$

Where $I$ is the intensity with an absolute temperature $T, E$ is the activation energy, $s$ is frequency factor, $\beta$ is heating rate and $b$ is the kinetic order, $n_{o}$ is the initial concentration of trapped carriers (McKeever, 1985). The deconvoluted result is shown in Fig. 9. The kinetic parameter of each peak is presented in Table II. The sequence number is according to Fig. 9 


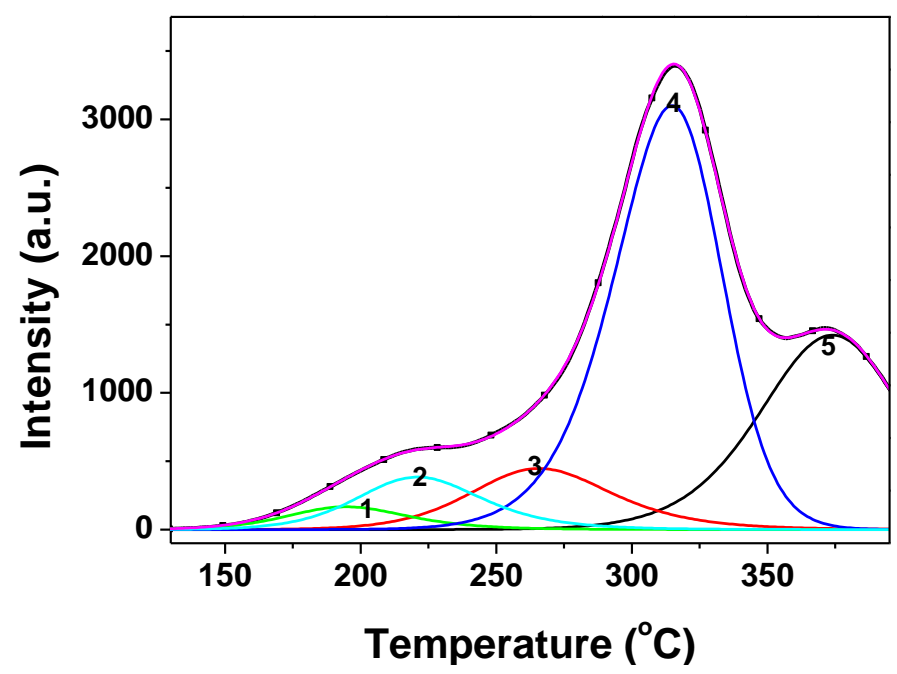

Fig. 9. TL deconvoluted curve of $\mathrm{Mg}_{2} \mathrm{SiO}_{4}$ : $\mathrm{Tb}$ (1h, 1 wt \%)

Table II. The kinetic parameter of $\mathrm{Mg}_{2} \mathrm{SiO}_{4}: \mathrm{Tb}(1 \mathrm{~h}, 1 \mathrm{wt} \%)$

\begin{tabular}{rcrccccc}
\hline Peak & $E(\mathrm{eV})$ & $\mathrm{b}$ & $s\left(\mathrm{~s}^{-1}\right)$ & $n_{0}$ & $T_{\max }$ & $\left({ }^{\circ} \mathrm{C}\right)$ & $I_{\max }$ \\
\hline 1 & 1.20 & 2 & $10^{12}$ & 1968 & 195 & 167 \\
2 & 1.29 & 2 & $10^{12}$ & 4733 & 221 & 384 \\
3 & 1.35 & 2 & $10^{12}$ & 6229 & 266 & 447 \\
4 & 1.73 & 1.3 & $10^{14}$ & 32169 & 315 & 3102 \\
5 & 1.77 & 1.7 & $10^{13}$ & 20049 & 374 & 1422 \\
\hline
\end{tabular}

\section{Discussion}

XRD result (Fig.1) shows that all the samples prepared at $1650{ }^{\circ} \mathrm{C}$ are consistent with the normal $\mathrm{Mg}_{2} \mathrm{SiO}_{4}$ phase. It has been discussed in our previous work that sintering temperature is one key factor to produce $\mathrm{Mg}_{2} \mathrm{SiO}_{4}$ (Wang et al., 2014). Although not displayed here, the glow curve becomes much simpler after this temperature treatment as the lower temperature peaks have been suppressed. The glow peak at $315{ }^{\circ} \mathrm{C}$ is the dominant peak, and this is suitable for radiation dosimetry. In addition, it produces a high response to the radiation exposure and emits the light within an ideal spectral frequency range (mostly in blue and green range) where photomultiplier tubes are efficient. So $\mathrm{Mg}_{2} \mathrm{SiO}_{4}: \mathrm{Tb}$ has excellent potential for use as a radiation dosimeter.

For comparison with other TL kinetic analyses at high heating rates the dosimetry peaks 
involve a process which displays an activation energy near $1.73 \mathrm{eV}$ for the dosimetry peak near $315{ }^{\circ} \mathrm{C}$ (Fig. 9 and Table II). Whilst an activation energy identifies a TL feature, it does not provide any details of the structure of the TL sites. Site modelling is also difficult as even for the $1 \%$ dopant level, and an ideal truly random dispersion of the $\mathrm{Tb}$, the long range interactions will imply that the sites are not entirely independent of other Tb sites. Further, in such high dopant situations the lattice strains and charge compensation features will cause lattice distortions that favour pairing or clustering of the dopants and associated intrinsic defects. Therefore, the trapping and recombination sites may be in intimate proximity. Hence there is no unique activation energy for the TL process, but instead the TL curve analysis subsumes these small variations into an effective single value. Local distortions are important in well ordered crystal structures, but more significant changes to the TL kinetics have been discussed in mineral systems where there are structural variations between different ordered and disordered phases (Sanchez-Munoz et al., 2016).

Both PL (Fig.3) and TL (Fig.5) emission spectra of $\mathrm{Mg}_{2} \mathrm{SiO}_{4}$ : $\mathrm{Tb}$ are dominated by characteristic emission lines of $\mathrm{Tb}^{3+}$. This is typical for rare earth doped TL dosimeters. However, there are obvious displacements of the TL peak temperatures as a function of wavelength, as shown in Table I. According to the classical model of TL, it is a simple process in which exposure to ionizing radiation, or UV light, can produce free electrons and/or holes. These become trapped at imperfections. Subsequent heating releases the charges and during their recombination and return to a ground state the energy release is in the form of light. In this idealized model, the trapping and recombination sites were assumed to be separate and it was then simple to model the processes in terms of a trap depth (E) as showed in Fig. 9. However, the peak temperatures of 
different emission bands are not the same, as shown in Table I. The peak values of emission lines are different. They can be divided into two groups. One group of emission lines $(383 \mathrm{~nm}, 420 \mathrm{~nm}$, $444 \mathrm{~nm}, 488 \mathrm{~nm})$ are in blue range and another group of lines $(551 \mathrm{~nm}, 595 \mathrm{~nm}, 623 \mathrm{~nm})$ are in red part. This is not a random pattern as the differences are consistent with the Tb energy level scheme shown in Fig. 10 (Dieke, 1968). The first group lines involve a range of upper states. Thus it means that the emission lines (recombination centers) are not totally isolated from the lattice imperfections that act as the trapping sites. The implication is that the trapping centers are closely coupled with the rare earth emission sites. The inherent distortions of the host lattice therefore mean the escape of charge from such traps will be modified. If the electron escapes and returns to the RE sites then the apparent TL peak temperatures will reflect this variation in stability and so the TL peaks will be wavelength dependent.

For a radiation dosimeter this is an excellent situation as it implies charge release will be totally efficient in generating the $\mathrm{Tb} \mathrm{TL}$ emission, and not in competition with processes of non-radiative trapping elsewhere in the lattice.

Fig. 10 relates the energy scheme of $\mathrm{Tb}$ ions to the various optical transitions and the pattern is that higher energy photons match the TL emissions which occur at lower temperature for the TL signals observed in this temperature range above room temperature. For closely coupled traps and $\mathrm{Tb}$ sites one may thus propose that the energy barrier is reduced compared for distant processes involving conduction band charge transport. Further, the local barrier will be crossed, or allow tunneling, between the trap potential well and the higher excited states of the $\mathrm{Tb}$. This means there is a preferential access path from the trap to high level Tb states and initially the TL curves will be predominantly displaying high energy photon emission. As such sites become emptied the lower 
wavelength signals will thus give a peak in the glow curve (as seen here).

Higher temperatures will then release charge from more distant trapping sites, perhaps with conduction band transport, and then excitation of the lower level upper states will become more effective. The net result is that the TL at long wavelengths will peak at higher temperatures than those at short wavelengths (i.e. precisely as seen here). The model proposed for this difference in peak temperature as a function of wavelength is consistent with the observations for this dosimeter in the TL above room temperature. In this temperature range the trapping sites are deep and there are often examples in this range of defects associated with the impurity sites.

It is important to note that whilst the same underlying principles of close association of traps and recombination sites, impurity clustering with charge compensators etc can occur over the entire temperature range (i.e. including below room temperature). There can be major difference in the stability of the sites and their component separations. Indeed, in this material the earlier low temperature TL data (Zhao et al., 2015) had also shown wavelength dependent TL peaks. The pattern matched the excited states of the $\mathrm{Tb}$ (and $\mathrm{Eu}$ ), but in that temperature range the pattern was reversed. This difference is not in conflict with the basic model of tunneling between trap and recombination sites. The only difference is that at low temperatures there can be more intimate contact and with the consequent thin energy barriers tunneling will initially favour population of the lower energy $\mathrm{Tb}$ states. 


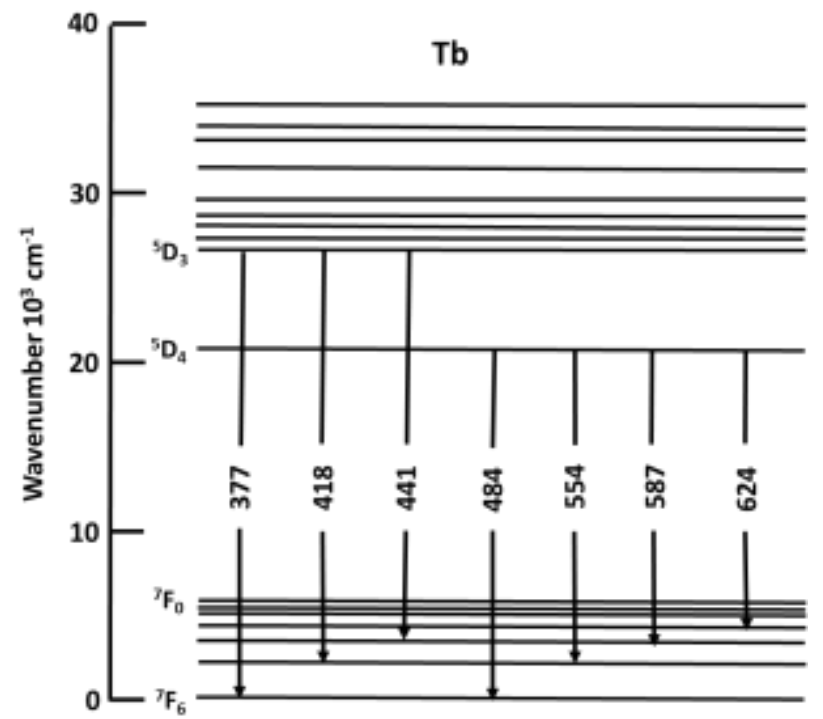

Fig. 10. Tb energy levels and their emission wavelengths in magnesium orthosilicate.

\section{Conclusion}

The performance of the $\mathrm{Tb}$ doped dosimetry material is sensitive to sintering conditions as well as the dopant concentration. Nevertheless, the heat treatments have not changed the basic lattice structure of the host magnesium silicate. The spectral data suggest that part of the reason for an efficient dosimeter material is the close association of traps and recombination sites and the evidence for this is demonstrated by a wavelength dependence of the TL peak temperatures of the Tb transitions.

\section{Acknowledgements}

We would like to thank Professor Qiang Tang for the discussion. This work was supported by the National Science Foundation of China (No.51472224, No.11205134) and the Fundamental Research Funds for the Central Universities of China.

\section{References}

Bacci, C., and Furetta, C., 1992. Kintetics parameters in $\mathrm{Mg}_{2} \mathrm{SiO}_{4}$ : Tb thermoluminescence 
material. J.Therm. Anal. 38, 1627-1633.

Dieke, G.H., 1968. Spectra and energy levels of rare earth ions in crystals, Wiley, New York. Ege, A., Wang, Y., and Townsend, P. D., 2007. Systematic errors in thermoluminescence. Nucl. Insts. and Methods A 576, 411-416.

Furetta, C., 2003. Handbook of Thermoluminescence. Rome University “La Sapienza”, Italy.

Hashizume, T., Kato, Y., Nakajima, T., Sakamoto, H., Kotera, N., Eguchi S., 1971. A new thermoluminescence dosemeter of high sensitivity using a magnesium silicate phosphor. In: Proceedings of the Symposium on Advanced Radiation Detectors, IAEA-SM143/11, Vienna, Austria.

Jun, J. S., Becker, K., 1975. Health Physics 28, 459-520.

Lakshmanan, A. R., Shinde, S. S., and Bhatt, R. C., 1978. Ultraviolet-induced thermoluminescence and phosphorescence in $\mathrm{Mg}_{2} \mathrm{SiO}_{4}$ : Tb. Phys. Med. Biol. 23, 952-960.

Lakshmanan, A. R., and Vohra, K. G., 1979. Gamma radiation induced sensitization and photo-transfer in $\mathrm{Mg}_{2} \mathrm{SiO}_{4}$ : Tb TLD phosphor. Nucl. Instrum. Methods 159, 585-592.

Mckeever, S.W.S., 1985, Thermoluminescnces of Solids, Cambridge University Press.

Mittani, J. C., Prokic, M., and Yukihara, E. G., 2008. Optically stimulated luminescence and thermoluminescence of terbium-activated silicates and aluminates. Radiat. Meas. 43, 323-326.

Miyoshi, T., Kobayashi, T., Shinohara, T., Okumura, K., Kaneda, T., 2004. Thermoluminescence of Laser-Irradiated $\mathrm{Mg}_{2} \mathrm{SiO}_{4}$ : Tb. Japanese J. Appl. Phys. 43, 6172-6173.

Mohan, N. S., Chen, R., 1970. Numerical curve fitting for calculating glow parameters. J. Phys. D. 3, 243-247.

Molina, P., Prokic, M., Marcazzo, J., Santiago, M., 2010. Characterization of a fiberoptic radiotherapy dosimetry probe base don $\mathrm{Mg}_{2} \mathrm{SiO}_{4}$ : Tb. Radiat. Meas. 45, 78-82.

Nakajima, T., 1972. Optical and thermal effects on thermoluminescence response of $\mathrm{Mg}_{2} \mathrm{SiO}_{4}(\mathrm{~Tb})$ and $\mathrm{CaSO}_{4}=(\mathrm{Tm})$ phosphors. Health Phys. 23, 133-136.

Prokic, M., and Yukihara, E. G., 2008, Dosimetric characteristics of high sensitive $\mathrm{Mg}_{2} \mathrm{SiO}_{4}$ : $\mathrm{Tb}$ solid TL detector. Radiat. Meas. 43, 463-466.

Sanchez-Munoz, L., Garcia-Guniea, J., Townsend, P. D., Juwono, T., and Cremades, A., 2016. Gaussian thermoluminescence in long-range disordered K-feldspar. American Mineralogist, 
$101,2118-2122$.

Shenker, D., Chen, R., 1971. Numerical curve fitting of general order kinetics glow peaks. J. Phys. D., 4, 287-291.

Wang, Y., Jiang, Y., Chu, X., Xu, J., and Townsend, P. D., 2014. Thermoluminescence responses of Terbium-doped Magnesium orthosilicate with different synthesis conditions. Radiat. Prot. Dosim. 158, 373-377.

Zhao, Y., Zhou, Y., Jiang, Y., Zhou, W., Finch, A.A., Townsend, P.D. and Wang, Y., 2015. Ion size effects on thermoluminescence of terbium and europium doped magnesium orthosilicate. J. Mater. Res. 30, 3443-3452. 